\title{
Amélie Schweiger, Flaubert en toutes lettres. L'écriture épistolaire dans la correspondance et dans l'œuvre
}

\section{Maria Emanuela Raffi}

\section{(2) OpenEdition}

1 Journals

\section{Edizione digitale}

URL: https://journals.openedition.org/studifrancesi/3167

DOI: $10.4000 /$ studifrancesi.3167

ISSN: 2421-5856

\section{Editore}

Rosenberg \& Sellier

\section{Edizione cartacea}

Data di pubblicazione: 1 juillet 2013

Paginazione: 478-479

ISSN: 0039-2944

Notizia bibliografica digitale

Maria Emanuela Raffi, «Amélie Schweiger, Flaubert en toutes lettres. L'écriture épistolaire dans la correspondance et dans l'œuvre», Studi Francesi [Online], 170 (LVII | II) | 2013, online dal 30 novembre 2015, consultato il 31 janvier 2023. URL: http://journals.openedition.org/studifrancesi/3167 ; DOI: https://doi.org/10.4000/studifrancesi.3167

Questo documento è stato generato automaticamente il 31 janvier 2023.

\section{(c)}

Creative Commons - Attribuzione - Non commerciale - Non opere derivate 4.0 Internazionale - CC BYNC-ND 4.0

https://creativecommons.org/licenses/by-nc-nd/4.0/ 


\title{
Amélie Schweiger, Flaubert en toutes lettres. L'écriture épistolaire dans la correspondance et dans l'œuvre
}

\author{
Maria Emanuela Raffi
}

\section{NOTIZIA}

AMÉLIE SCHWEIGER, Flaubert en toutes lettres. L'écriture épistolaire dans la correspondance et dans l'œuvre, Publications des universités de Rouen et du Havre, 2012, pp. 140.

1 In questo studio sulla scrittura epistolare di Flaubert, l'A. pone anzitutto il problema della separazione fra scrittura delle opere e scrittura delle lettere, considerata quest'ultima dal suo autore, sempre preoccupato della confidenzialità dei testi, come esercizio secondario, quando non «passablement nulle». L'«intimité» che caratterizza il genere epistolare si estende, nel periodo giovanile di Flaubert, a tutta l'opera, sempre concepita per un destinatario specifico, reale o immaginario. Alfred Le Poittevin, Louis Bouilhet, George Sand, Louise Colet sono i destinatari successivi e privilegiati di Mémoires d'un fou, Agonies, Loys XI, della prima versione della Tentation de Saint Antoine o del progetto di Un coeur simple. Prima di arrivare all'impersonalità di Madame Bovary, la scrittura di Flaubert mostra con il suo tenace attaccamento alla categoria dell' «intime», alla condivisione con un destinatario, la forte presenza della soggettività che la caratterizza e «la résistance du sujet à s'effacer de son œuvre» testimoniata anche dalla grande "porosité entre créateur et creatures fictives».

2 Alla luce del parallelismo stabilito fra opera giovanile e stile epistolare, l'A. prende successivamente in esame la tematizzazione della lettera nelle opere giovanili (Un secret de Philippe le Prudent, Passion et Vertu e la prima Éducation sentimentale), dove appare l'impossibilità di una reale comunicazione, per passare poi all'esame delle lettere giovanili, esaminate sia per le formule adottate sia per i contenuti, con particolare 
attenzione alle lettere indirizzate a Louise Colet, di volta in volta feticcio mitizzato e quasi autoriflettente, musa ispiratrice, interlocutrice in materia d'arte.

Un capitolo a parte occupano «les lettres d'Orient», collocate alla fine del periodo «de jeunesse» e all'inizio della vera e propria esperienza artistica, di cui sembrano seguire e favorire la maturazione. Ne scaturisce, ma ancora incerta, «une sorte de mythologie de l'artiste» che prefigura la difficoltà del Flaubert di Madame Bovary di trovare un modello di riferimento al di fuori dell'immagine romantica, ancora viva ma ormai inattuale. Come accadrà nell'opera narrativa, «l'ironie voisine avec la nostalgie» e la modernità vi si caratterizza come instabile e transitoria.

4 Un capitoletto conclusivo è infine dedicato all'ultima corrispondenza di Flaubert, dopo Madame Bovary: corrispondenza sintetica, funzionale, spesso segnata da indicazioni banali quando non dalla formula annichilente «rien à dire», quasi che, in un movimento inverso, l'opera impersonale di Flaubert avesse ridisegnato anche le possibilità espressive del genere epistolare. 